\title{
Densification and fine grain formation mechanisms of BaTiO3 ceramics consolidated by self-assembly sintering
}

\section{Quan Jin}

Northwest University

Lili Zhao

Northwest University

Xiaoting Zhang

Northwest University

Run Zhang

Northwest University

Bin Cui ( $\nabla$ cuibin@nwu.edu.cn )

Northwest University https://orcid.org/0000-0002-8489-0084

\section{Original Research}

Keywords: contact angle, free energy, apparent activation energy, relative density

Posted Date: February 10th, 2021

DOI: https://doi.org/10.21203/rs.3.rs-202938/v1

License: (c) (1) This work is licensed under a Creative Commons Attribution 4.0 International License. Read Full License

Version of Record: A version of this preprint was published at Journal of Materials Science: Materials in Electronics on February 25th, 2021. See the published version at https://doi.org/10.1007/s10854-02105527-z. 


\title{
Densification and fine grain formation mechanisms of $\mathrm{BaTiO}_{3}$
}

\section{ceramics consolidated by self-assembly sintering}

\author{
Quan Jin ${ }^{1}$, Lili Zhao ${ }^{2}$, Xiaoting Zhang ${ }^{1}$, Run Zhang ${ }^{1}$, Bin Cui ${ }^{1 *}$
}

1. Key Laboratory of Synthetic and Natural Functional Molecule (Ministry of

Education), Shaanxi Key Laboratory of Physico-Inorganic Chemistry, College of Chemistry \& Materials Science, Northwest University, Xi'an, Shaanxi 710127, China

2. School of Information Science and Technology, Northwest University, Xi'an, Shaanxi 710127, China

E-mail address: cuibin@nwu.edu.cn. 
Abstract: In this paper, from the perspective of thermodynamics and kinetics, we have studied the mechanism of balancing the densification and grain growth via co-sintering the micron and nano powders, also known as self-assembly sintering. In the experiment, the $200 \mathrm{~nm}$ and $80 \mathrm{~nm} \mathrm{BaTiO}_{3}$ spherical powders were used as models for combination and co-sintering. In terms of thermodynamics, the contact angle method is applied to determine the free energy of the binary particle size system. The surface free energy of $200 \mathrm{~nm}$ and $80 \mathrm{~nm} \mathrm{BaTiO}_{3}$ powders are $51.66 \mathrm{~J} / \mathrm{mol}$ and 203.47 J/mol, respectively. When the powder ratio is $1: 1$, the surface free energy of the binary particle size system is $127.56 \mathrm{~J} / \mathrm{mol}$, which is the reason for the balance between densification and grain growth. In terms of kinetics, the Arrhenius equation was utilized to calculate the apparent activation energy $(Q)$ of the binary particle size system. The results show that the value of $Q$ is $360 \mathrm{~kJ} / \mathrm{mol}$ at $1000{ }^{\circ} \mathrm{C}$. The fine-grained ceramics with high relative density obtained by this sintering method at a low sintering temperature $\left(1000{ }^{\circ} \mathrm{C}\right)$ can be explained by the relative low value of $Q$.

Keywords: contact angle; free energy; apparent activation energy; relative density 


\section{Introduction}

Fine-grained ceramics with high relative density have attracted the attention of researchers due to their excellent mechanical properties, high breakdown field strength, excellent dielectric properties and good energy storage properties [1-5]. Since the densification process and grain growth are contradictory, the preparation of fine grained ceramics with high relative density is still a major challenge [3-5]. Up to now, the fine-grained ceramics with relatively high relative density can be obtained by hot pressing sintering, spark plasma sintering, cold sintering, two-step sintering and electric field sintering [6-10]. However, it is difficult to achieve this goal under normal conditions, that is, using a muffle furnace at atmospheric pressure [11-13]. This problem is closely related to the size of the powders. Using micron powders for sintering, the ceramics with high relative density can not be obtained, because of the high sintering window temperature and which being close to the powder melting point [14]. When nano powders are used for sintering, the sintering window temperature is relative low and whose range is narrow [15]. Nano powders can be used to obtain high relative density ceramics, but the grain growth cannot be avoided, and the coarse-grained ceramics are usually formed [15-17]. Generally, the methods, including the hot pressing sintering, spark plasma sintering, cold sintering, two-step sintering and electric field sintering, usually involve sintering equipment and complex microstructure design (such as core-shell structure design) [6-10]. From the perspective of energy saving and convenience, it is of great significance to develop a sintering method that can be used under normal conditions in order to obtain fine-grained ceramics with high relative density [13-15]. 
As mentioned above, the size of the powders plays a decisive role in the sintering performance. Studies have shown that using the intrinsic properties of powders, such as morphology, size and so on, through the combination of powders with different sizes then co-sintering, the contradiction between densification and grain growth can be balanced [18-24]. Consequently, the fine-grained ceramics with high relative density can be obtained by sintering under conventional conditions [20-24]. For example, J W Oh et.al [21] used the Fe powders with sizes $3 \mu \mathrm{m}$ and $100 \mathrm{~nm}$ to co-sintering. The ceramics with high relative density of $92.5 \%$ and grain size with 4.1 $\mu \mathrm{m}$ can be obtained. $\mathrm{H}$ Y Xu et.al [22] utilized the same way to synthesize the $\mathrm{Al}_{2} \mathrm{O}_{3}$ dense fine-grained ceramics by $3 \mu \mathrm{m}$ and $220 \mathrm{~nm} \mathrm{Al}_{2} \mathrm{O}_{3}$ powders, whose relative density is $92.2 \%$ and grain size is $250 \mathrm{~nm}$. The researchers found that when combining two sizes of powders, the key point is that the sizes must meet the requirements of the close-packed model, because it can maximize the space utilization [23-27]. X Y Zhai et.al [23] and Q Jin et.al [24] have achieved indium tin oxide (ITO) and $\mathrm{BaTiO}_{3}$ fine-grained ceramics with high relative density under conventional sintering conditions, respectively. They considered that this method is similar to the self-assembly process of colloidal crystal, and named this way as a self-assembly sintering method [24]. What is more, researchers have pointed out the requirements met by the two sizes of powders and their reasonable ratios by the calculations of close packing model, and gave the general conditions for this method [22-24].

At present, the sintering mechanism of the hot pressing sintering, spark plasma sintering, cold sintering, two-step sintering and electric field sintering have been 
studied [6, 9, 27-30]. The previous researches conducted from the perspectives of synthesis methods, phase composition, physical changes, chemical changes and propertie $[6,9,27-30]$. However, there is a lack of research on the mechanism of the self-assembly sintering method. In this paper, from the ceramic sintering thermodynamics and kinetics, and the view point of the intrinsic properties of powders, we utilized the $200 \mathrm{~nm}$ and $80 \mathrm{~nm} \mathrm{BaTiO}_{3}$ powders as a research model, combining them with a ratio of 1:1 to form a binary system and co-sintering. The contact angle is used to study the sintering force (Gibbs Free Energy, $G$ ) of the binary particle size system, and the Arrhenius equation is used to study the apparent activation energy $(Q)$, which can explain how to balance the contradiction between the densification of ceramics and the grain growth. We presented a way to study the mechanism of controlling the synthesis of $\mathrm{BaTiO}_{3}$ dense and fine-grained ceramics by the binary particle size sintering method at a relative low temperature $\left(1000{ }^{\circ} \mathrm{C}\right)$.

\section{Experimental Procedures}

\subsection{Materials}

Raw materials of $\mathrm{Ba}(\mathrm{Ac})_{2}$ (99\% purity), $\mathrm{TiCl}_{4}$ (99\% purity), $\mathrm{NaOH}$ (99\% purity), $\mathrm{CH}_{3} \mathrm{CH}_{2} \mathrm{OH}$ (99.7\% purity) and $\mathrm{HAc}(36 \%$ purity) were all analytical-grade chemicals. They were purchased from Tianjin Damao Chemical Industry Co., Ltd.

\subsection{Preparation of the $\mathrm{BaTiO}_{3}$ powders particles}

The monodispersed $\mathrm{BaTiO}_{3}$ powders particles with mean size of $200 \mathrm{~nm}$ and 80 $\mathrm{nm}$ were prepared respectively, and their $\mathrm{Ba} / \mathrm{Ti}$ is $1: 1$, using a co-precipitation approach through adjusting the concentration of the precipitant [24]. The morphology 
and phase of the as-prepared $\mathrm{BaTiO}_{3}$ powders particles can be seen in Fig. S1 and Fig. $\mathrm{S} 2$. The $\mathrm{BaTiO}_{3}$ powders particle size distributions and the calculation values of the specific surface area can be seen in Fig. S3 and Supplementary Information.

\subsection{Preparation of the $\mathrm{BaTiO}_{3}$ ceramics}

In a typical synthetic process, the large and the small powders particles with weight of $0.5 \mathrm{~g}$ were ultrasonically dispersed in absolute ethanol respectively, labeled as A and B suspension respectively. While mechanically stirring the A suspension, the B suspension was slowly added into it. After stirring for $4 \mathrm{~h}$, the $\mathrm{C}$ suspension was

obtained. The $\mathrm{C}$ suspension was evaporated to dry at $50{ }^{\circ} \mathrm{C}$ in an oven for $24 \mathrm{~h}$. Then the particles were pressed into pellets with $6 \mathrm{MPa}(\sim 8 \mathrm{~mm}$ of diameter and $\sim 1.5 \mathrm{~mm}$ of thickness), and sintered at $1000{ }^{\circ} \mathrm{C}$ for $2-14 \mathrm{~h}$.

\subsection{Characterization Methods}

The phase structures of the $\mathrm{BaTiO}_{3}$ powders and ceramics were checked by X-ray diffraction $\left(\mathrm{XRD}\right.$; angular step interval: $0.02^{\circ}$, Advance, Bruker, Frankfurt, Germany) at room temperature using $\mathrm{Cu} K \alpha$ radiation $(K \alpha=1.5418 \AA$ ) in the $2 \theta$ range of $20^{\circ}-70^{\circ}$ with a scan rate of $0.1^{\circ}$ s. The microstructure of the $\mathrm{BaTiO}_{3}$ powders and ceramics were characterized by scanning electron microscope (SEM, Quanta-600, FEI, USA). The particles size and grain size were determined by measuring the grains from the SEM micrograph through a linear intercept method. The surface area of the $\mathrm{BaTiO}_{3}$ powders was calculated by the particles size distribution of the $\mathrm{BaTiO}_{3}$ powders obtained through the Laser Particle Size Analyzer (temperature: $25.0{ }^{\circ} \mathrm{C}$, dispersant: water, absorbtion: 0.01, refractive index: 1.520, Malvern Instruments Ltd, 
England). The grain size distribution was calculated by using the analytical software named Nano Measurer. The densities were measured by the Archimedes method using water as the liquid media, and a theoretical density of $6.02 \mathrm{~g} / \mathrm{cm}^{3}$ was adopted for the $\mathrm{BaTiO}_{3}$ ceramics. The relative density is the ratio of the measured density to the theoretical density. The dielectric properties of the $\mathrm{BaTiO}_{3}$ ceramics were evaluated by a LCR tester (Model HP4284A, Hewlett-Packard, USA) at $1 \mathrm{kHz}$ ranging from -60 to $130{ }^{\circ} \mathrm{C}$. The water contact angle (WCA) and cetane contact angle (CCA) of the $\mathrm{BaTiO}_{3}$ powders surface were recorded by video contact angle measurement system (DSA25, KRÜSS, Germany). $2 \mu \mathrm{L}$ of deionized water and cetane were dripped on the dried $\mathrm{BaTiO}_{3}$ green body with a syringe. The contact angles were measured by software named Drop Shape Analysis. For emission transmission electron microscopy (TEM) measurements, the ceramics were polished by a fine grade of sandpaper, diamond abrasives and argon-ion beam milling (Precision Ion Polishing System 691, Gatan), respectively.

\section{Results and Discussion}

\subsection{Effect of the powders ratios on the composition and morphology of the}

\section{$\mathrm{BaTiO}_{3}$ ceramics}

Fig. 1 shows that the ceramics obtained by different ratios of the $\mathrm{BaTiO}_{3}$ powders are tetragonal perovskite. The XRD peak shifts to high angle, which indicates that the unit cell decreases with the increase of the ratio of $200 \mathrm{~nm} \mathrm{BaTiO}_{3}$ powders, which is related to the decrease of grain size. In addition, the degree of the XRD peak intensity gradually weakened from $44^{\circ}$ to $46^{\circ}$. Generally speaking, for the 
pure tetragonal phase $\mathrm{BaTiO}_{3}$ ceramics, the integrated area of the diffraction peak of (200) crystal plane is larger than that of the (002) crystal plane. As the grain size decreases, the difference in the integrated area of the diffraction peaks between the two becomes small, displaying that the content of tetragonal phase decreases gradually. Researches show that the phase transition and cell distortion of the ceramics are affected by composition and grain size [16, 17]. Because the composition of the as-obtained ceramics is $\mathrm{BaTiO}_{3}$, the phase change and cell distortion are mainly affected by the grain size [16]. According to the grain size effect, with the grains becoming smaller, the internal stress caused by the grain distortion would be enhanced, and the cell distortion dose not occur easily, leading to the phase transform from the tetragonal to the cubic $[9,16,17]$. Therefore, when the grain size decreases, the tetragonal phase decreases with increasing $200 \mathrm{~nm}$ powders. For the further explanation, the grain size changes are discussed in detail below.

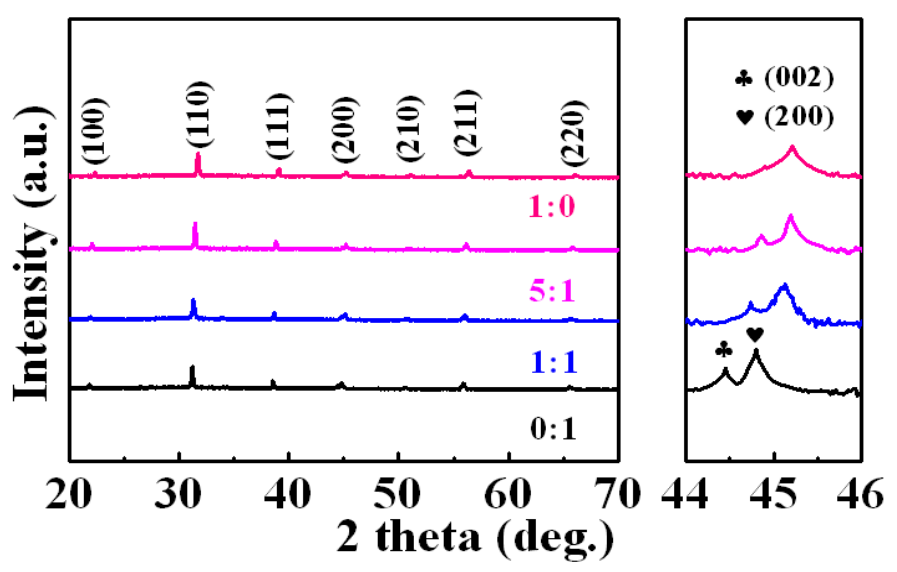

Fig. 1 XRD patterns of the $\mathrm{BaTiO}_{3}$ ceramics obtained by different ratios of the $\mathrm{BaTiO}_{3}$ powders. The ratio of $0: 1$ represents the ratio of $200 \mathrm{~nm}$ powders to $80 \mathrm{~nm}$ powders. Other ratios have the same meanings.

Fig. 2 displays the dielectric properties of ceramics. As the ratio of the $200 \mathrm{~nm}$ 
powders increases, the relative density decreases continuously, the overall dielectric permittivity decreases due to the reducation of the relative density (Table I). The value of maximum dielectric permittivity $\left(\varepsilon_{\max }\right)$ decreases with the grain size decreasing. Furthermore, the relative density decreases as the ratio of the $200 \mathrm{~nm}$ powders increases, resulting in an increase in the $\tan \delta$. Due to the grain size effect, the sharpness of the Curie peak of the samples becomes low gradually with the decreasing grain size $[16,17]$.
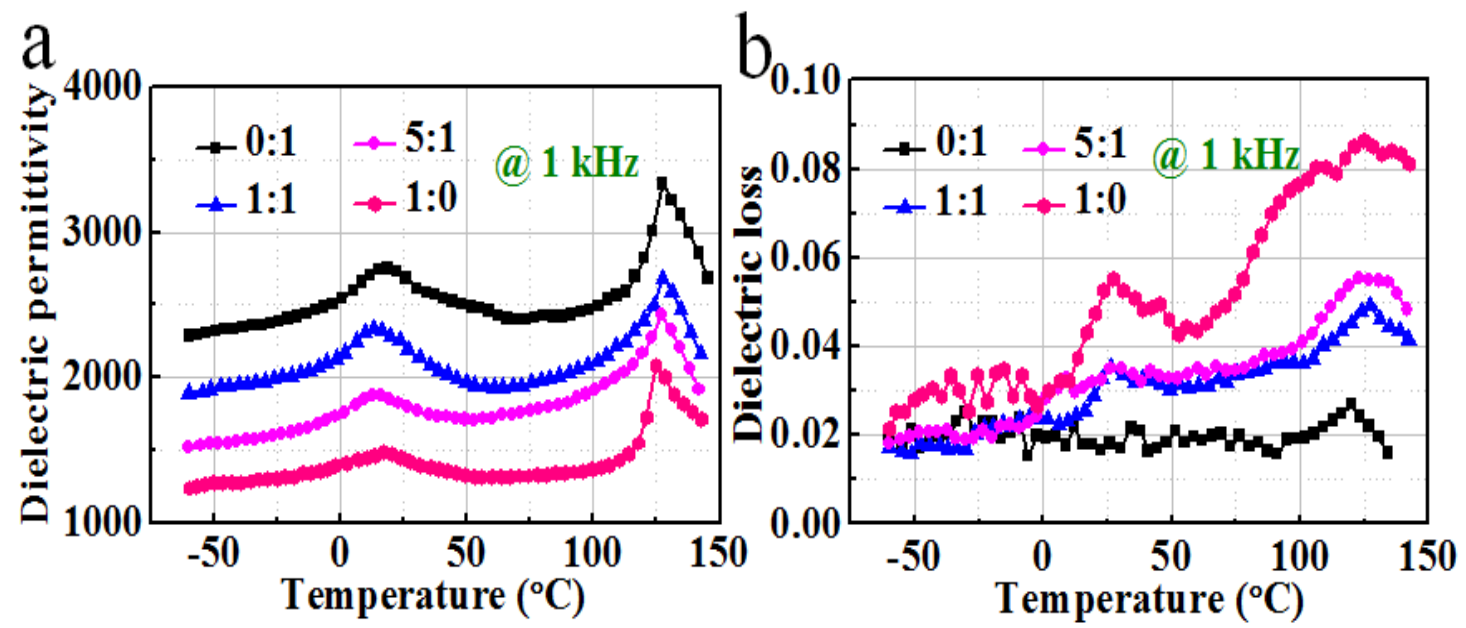

Fig. 2 (a) The dielectric permittivity and (b) the dielectric loss of the samples obtained by different ratios of the $\mathrm{BaTiO}_{3}$ powders.

Fig. 3 shows the morphologies of the $\mathrm{BaTiO}_{3}$ ceramics obtained by different ratios of the $\mathrm{BaTiO}_{3}$ powders. With the increase of the ratios of $200 \mathrm{~nm} \mathrm{BaTiO}_{3}$ powders, the large grain size decreases from $2656 \mathrm{~nm}$ to $216 \mathrm{~nm}$. What is more, the relative density decreases with the increase of the proportion of $200 \mathrm{~nm} \mathrm{BaTiO}_{3}$ powders. That means the powder ratio has a significant effect on the relative density and grain size of the ceramics (Table I). The results show that the sintering activity of the system changes with the different ratios of the powders, leading to great difference 
in grain size and relative density. Due to the influence of space packing effect and surface free energy, increasing the proportion of $200 \mathrm{~nm} \mathrm{BaTiO}_{3}$ powders can reduce the space packing effect and surface free energy, which reduces the sintering force, hinders the grain boundary diffusion and grain boundary migration. Finally, it makes the ceramics difficult to densification and the grains difficult to grow. On the contrary, the addition of $80 \mathrm{~nm} \mathrm{BaTiO}_{3}$ powders can improve the sintering activity and promote the densification and grain growth. However, excessive $80 \mathrm{~nm} \mathrm{BaTiO}_{3}$ powders result in too small curvature and high sintering activity, causing the grain boundary migration and abnormal grain growth. That is not conducive to the preparation of fine-grained ceramics. When the sintering activity of $\mathrm{BaTiO}_{3}$ powders is balanced, whih the powder ratios being appropriate, the densification process and grain growth are balanced. Consequently, when the ratio is $1: 1$, the fine-grained $\mathrm{BaTiO}_{3}$ ceramics with grain size of $252 \mathrm{~nm}$ and relative density of $92 \%$ can be achieved at relative low temperature $1000{ }^{\circ} \mathrm{C}$. The reasons for adopting this sintering method to obtain fine-grained ceramics with higher relative density are as follows:

(1) The space packing effect: the $80 \mathrm{~nm}$ powders can fill in the voids formed by the $200 \mathrm{~nm}$ powders to improve the space utilization due to the decrease of Gibbs free energy, thereby increasing the relative density of the ceramics.

(2) The surface free energy: Generally, under the certain sintering conditions, the sintering force is determined by the surface energy of the powders. The $200 \mathrm{~nm}$ powders with low surface free energy have low sintering force, and $80 \mathrm{~nm}$ powders with high surface free energy correspongding high sintering force. When the ratio of 
the two is appropriate, the sintering force of the system can be balanced.

(3) The apparent activation energy: The apparent activation energy determines the sintering temperature. The lower the apparent activation energy is, the lower the sintering temperature is.

As the space packing effect is well known, the surface free energy and the apparent activation energy are discussed in details below.
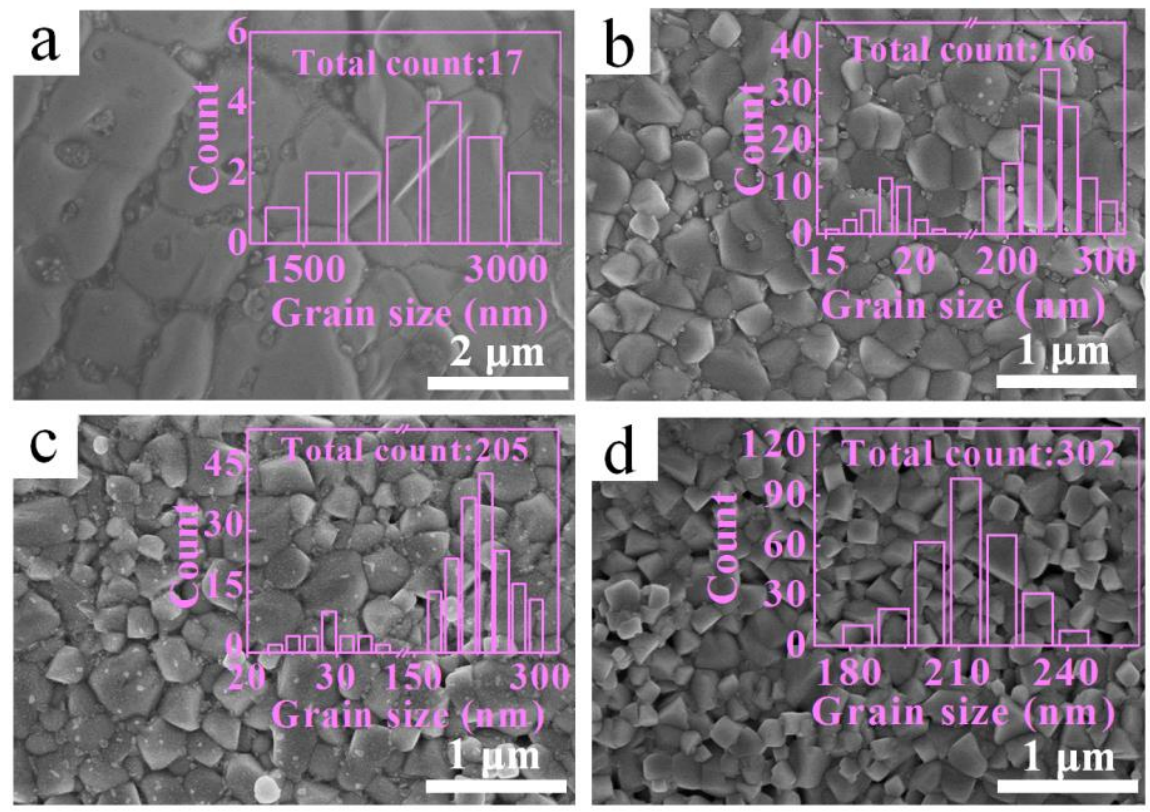

Fig. 3 SEM micrographs of the $\mathrm{BaTiO}_{3}$ ceramics obtained by different ratios of the $\mathrm{BaTiO}_{3}$ powders: (a) 0:1, (b) 1:1, (c) 5:1 and (e) 1:0.

Table I. Summary of parameters of the $\mathrm{BaTiO}_{3}$ ceramics by different ratios of the $\mathrm{BaTiO}_{3}$ powders.

\begin{tabular}{ccccccc}
\hline Sample & $\begin{array}{c}\text { Mean grain } \\
\text { size }(\mathrm{nm})\end{array}$ & $\begin{array}{c}\text { Density } \\
\left(\mathrm{g} / \mathrm{cm}^{3}\right)\end{array}$ & $\begin{array}{c}\text { Relative } \\
\text { Density }\end{array}$ & $\varepsilon_{\max }$ & $\varepsilon_{r}$ & tan $\delta$ \\
\hline $0: 1$ & 2656 & 5.659 & $94 \%$ & 3332 & 2685 & 0.027 \\
$1: 1$ & $252(78 \%) / 18(22 \%)$ & 5.538 & $92 \%$ & 2692 & 2192 & 0.049 \\
$5: 1$ & $242(83 \%) / 28(17 \%)$ & 5.059 & $84 \%$ & 2436 & 1802 & 0.055 \\
$1: 0$ & 216 & 4.515 & $75 \%$ & 2078 & 1422 & 0.086 \\
\hline
\end{tabular}

\subsection{The surface free energy}


As mentioned above, the sintering force of ceramics is determined by the surface free energy of $\mathrm{BaTiO}_{3}$ powders $[31,32]$. By measuring the contact angle (CA) at room temperature, the surface free energy of $\mathrm{BaTiO}_{3}$ powders at room temperature can be determined to qualitatively explain the influence of $80 \mathrm{~nm}$ and $200 \mathrm{~nm}$ powders on the sintering force. The CA method is often used to measure the contact angle between powder and specific liquid, and then the corresponding surface free energy can be obtained through calculation $[33,34]$. The dispersion force $\left(\gamma_{l}^{d}\right)$ and the polarity force $\left(\gamma_{l}^{p}\right)$ of specific liquid are required to test the contact angle of powders, whose specific data are shown in Table II $[33,34]$.

Table II. Surface energy components of water and hexadecane

\begin{tabular}{cccc}
\hline Liquid & $\gamma_{l}^{d}\left(\mathrm{~mJ} / \mathrm{m}^{2}\right)$ & $\gamma_{l}^{p}\left(\mathrm{~mJ} / \mathrm{m}^{2}\right)$ & $\gamma_{l}\left(\mathrm{~mJ} / \mathrm{m}^{2}\right) *$ \\
\hline Water & 21.8 & 51.0 & 72.8 \\
Cetane & 27.3 & 0 & 27.3 \\
\hline
\end{tabular}

*The $\gamma_{l}$ means the surface free energy of specific liquid.

Fig. 4 demonstrates the WCA and CCA of $80 \mathrm{~nm}$ and $200 \mathrm{~nm} \mathrm{BaTiO}_{3}$ powders. The WCA $\left(11.3^{\circ}\right.$ and $\left.13.5^{\circ}\right)$ of $80 \mathrm{~nm} \mathrm{BaTiO} 3$ powder are large, and the CCA $\left(57.0^{\circ}\right.$ and $57.6^{\circ}$ ) are small, indicating that they has strong hydrophilicity. But the CA of 200 nm $\mathrm{BaTiO}_{3}$ powders show the opposite results, and whose WCA is larger than that of the CCA, displaying strong hydrophobicity. In general, the hydrophilic powders have high surface free energy. Consequently, from the qualitative point of view, the $80 \mathrm{~nm}$ $\mathrm{BaTiO}_{3}$ powders have larger surface free energy than that of the $200 \mathrm{~nm} \mathrm{BaTiO}_{3}$ powders. Additionally, the penetration time of the water droplets in $80 \mathrm{~nm} \mathrm{BaTiO}_{3}$ powders was short $(0.47 \mathrm{~s})$, while it was long (7.02 s) at the $200 \mathrm{~nm} \mathrm{BaTiO}_{3}$ powders. 
The penetration time of cetane droplet at the $80 \mathrm{~nm} \mathrm{BaTiO} 3$ powders and the $200 \mathrm{~nm}$ $\mathrm{BaTiO}_{3}$ powders are $1.79 \mathrm{~s}$ and $2.24 \mathrm{~s}$, respectively. The results of penetration time test show that the $80 \mathrm{~nm} \mathrm{BaTiO}$ powders have strong hydrophilicity, and the $200 \mathrm{~nm}$ $\mathrm{BaTiO}_{3}$ powders have strong hydrophobicity, which is consistent with the contact angle test results. These also prove the $80 \mathrm{~nm} \mathrm{BaTiO}$ powders with large surface free energy and the $200 \mathrm{~nm}$ ones with relatively small surface free energy. When the two are mixed to form a binary particle size system, the difference of the surface free energy between them is easy to induce self-assembly [35]. According to Owens Wendt equation (1), we can quantitatively determine the surface free energy of the binary particle size system [33].

$$
\gamma_{s l}=\gamma_{s}+\gamma_{l}-2\left(\gamma_{s}^{d} \gamma_{l}^{d}\right)^{1 / 2}-2\left(\gamma_{s}^{p} \gamma_{l}^{p}\right)^{1 / 2}
$$

Where, the surface free energy of solid-liquid interface is represented by $\gamma_{s l}$, the surface free energy of solid and liquid are $\gamma_{s}$ and $n$ respectively, $\gamma_{s}^{d}$ and $\gamma_{s}^{p}$ mean the dispersion force and the polarity force of the solid respectively. By combining the equation (1) with the young's equation $\left(\gamma_{s}=\gamma_{s l}+\gamma_{l} \cos \theta\right)$, we can get the equation (2) as follow:

$$
\frac{\gamma_{l}(\cos \theta+1)}{2\left(\gamma_{l}^{d}\right)^{1 / 2}}=\left(\gamma_{s}^{p}\right)^{1 / 2} \frac{\left(\gamma_{l}^{p}\right)^{1 / 2}}{\left(\gamma_{l}^{d}\right)^{1 / 2}}+\left(\gamma_{s}^{d}\right)^{1 / 2}
$$

Where, $\theta$ is the CA, whose schematic diagram is shown in Fig. 5. 

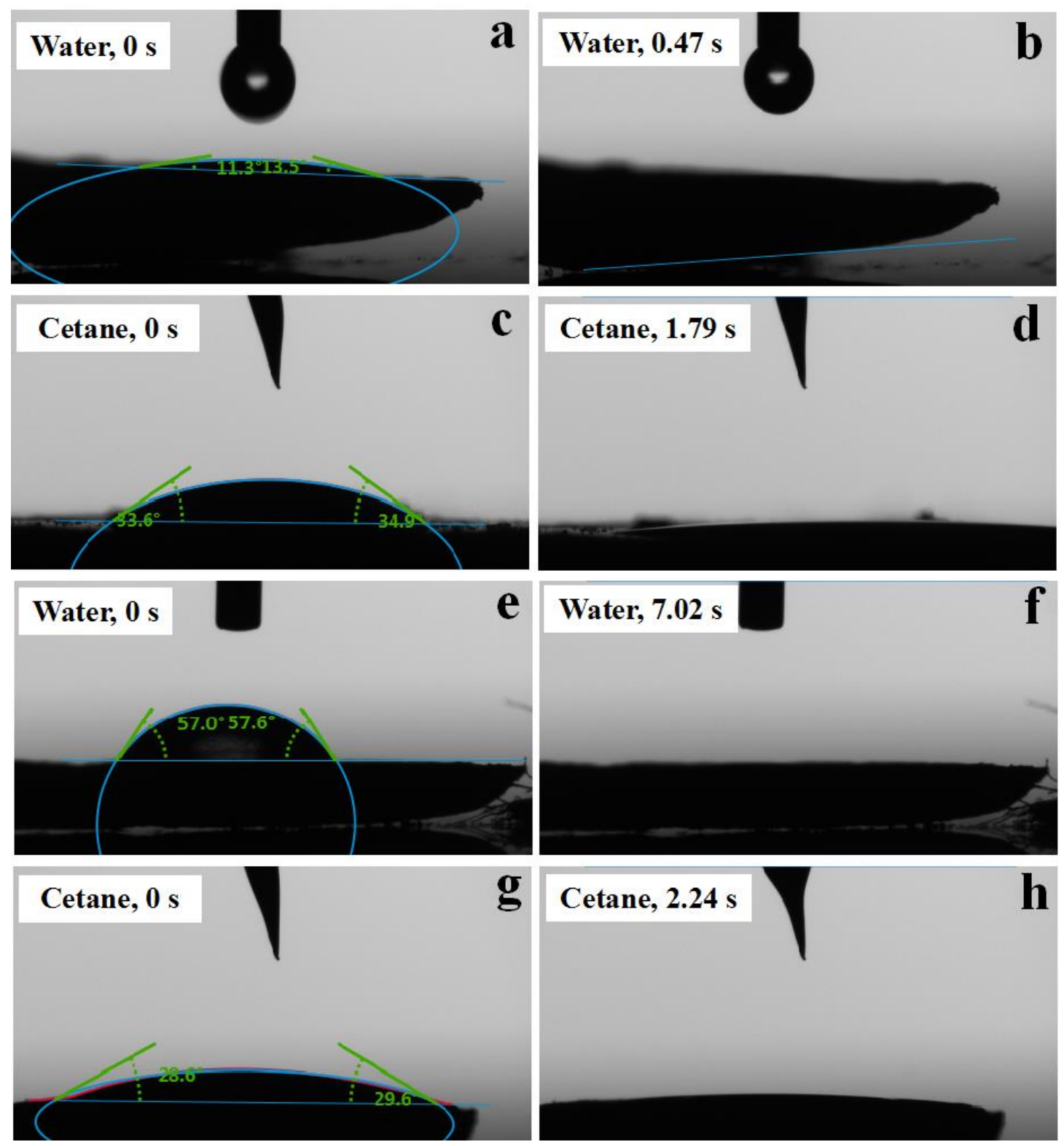

Fig. $4 \mathrm{CA}$ images of the $80 \mathrm{~nm} \mathrm{BaTiO}_{3}$ powders: (a) start (water), (b) end (water), (c)

start (hexadecane) and (d) end (hexadecane), CA images of the $200 \mathrm{~nm} \mathrm{BaTiO}_{3}$

powders: (e) start (water), (f) end (water), (g) start (hexadecane) and (h) end

(hexadecane). 


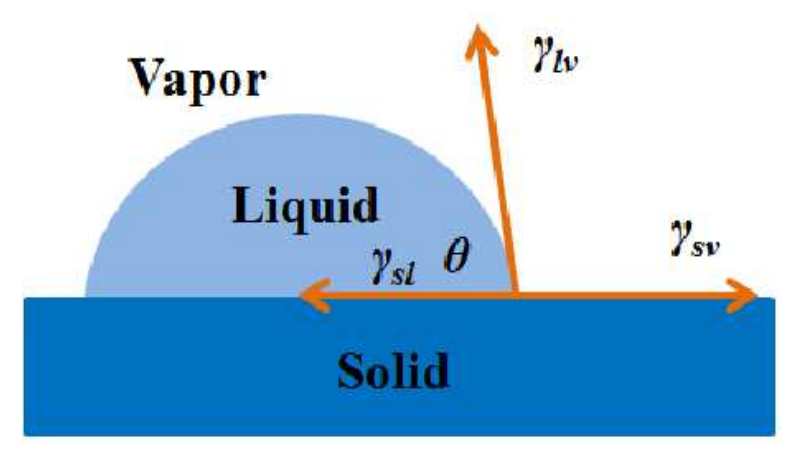

Fig. 5 Schematic diagram of the contact angle.

Fig. 6a shows the CA values of the $80 \mathrm{~nm}$ and the $200 \mathrm{~nm} \mathrm{BaTiO}_{3}$ powders. Substituting the CA values and the values of the $\gamma_{l}^{d}$ and $\gamma_{l}^{p}$ in Table II into the equation (2) and then linear fitting, the $\gamma_{s}$ values of the $80 \mathrm{~nm}$ and the $200 \mathrm{~nm} \mathrm{BaTiO}$ powders are 70.06 and $44.47 \mathrm{~mJ} / \mathrm{m}^{2}$, respectively (Fig. 6b). According to the thermodynamics, the total surface free energy (Gibbs free energy, $G$ ) of the system is the sintering force. For $1 \mathrm{~mol}$ spherical particles with radius $R$, the following equation is satisfied:

$$
N=\frac{3 M}{4 \pi R^{3} \rho}=\frac{3 V_{m}}{4 \pi R^{3}}
$$

Where $M$ is the molecular weight of the $\mathrm{BaTiO}_{3}$ powders, $\rho$ is its density, and $V_{m}$ is its molar volume. According to the equation (4), the total surface area $\left(S_{A}\right)$ of the $\mathrm{BaTiO}_{3}$ powders is obtained.

$$
S_{A}=4 \pi R^{2} N=\frac{3 V_{m}}{R}
$$

When the temperature and pressure are determined, the $G$ satisfies the following equation (5):

$$
G=\frac{3 \gamma_{s} V_{m}}{R}
$$

According to equation (5), the $G$ values of the $80 \mathrm{~nm}$ and the $200 \mathrm{~nm} \mathrm{BaTiO}_{3}$ powders 
are $203.47 \mathrm{~J} / \mathrm{mol}$ and $51.66 \mathrm{~J} / \mathrm{mol}$, respectively. When the powder ratio is $1: 1$, the $G$ value of the system is $127.56 \mathrm{~J} / \mathrm{mol}$. Furthermore, we measured the particle size of the $\mathrm{BaTiO}_{3}$ powders by the method of a laser particle size analyzer, and found that the specific surface area of the $80 \mathrm{~nm}$ and $200 \mathrm{~nm} \mathrm{BaTiO} 3$ powders are $10.2802 \mathrm{~m}^{2} / \mathrm{g}$ and $4.5953 \mathrm{~m}^{2} / \mathrm{g}$, respectively (Fig. S3 and Supplementary Information). The $G$ values of the $80 \mathrm{~nm}$ and the $200 \mathrm{~nm} \mathrm{BaTiO}_{3}$ powders obtained by the experimental results are $167.81 \mathrm{~J} / \mathrm{mol}$ and $47.61 \mathrm{~J} / \mathrm{mol}$, respectively. The $G$ value of the binary particle size system is $107.71 \mathrm{~J} / \mathrm{mol}$ (the details in Supplementary Information). The experimental and the calculated results display that the sintering force of the binary particle size system provided by the surface free energy is much higher than that of the $200 \mathrm{~nm}$ $\mathrm{BaTiO}_{3}$ powders only. Compared with the $80 \mathrm{~nm} \mathrm{BaTiO}$ powders only, the sintering force is relatively small, thus balancing the densification and grain growth.
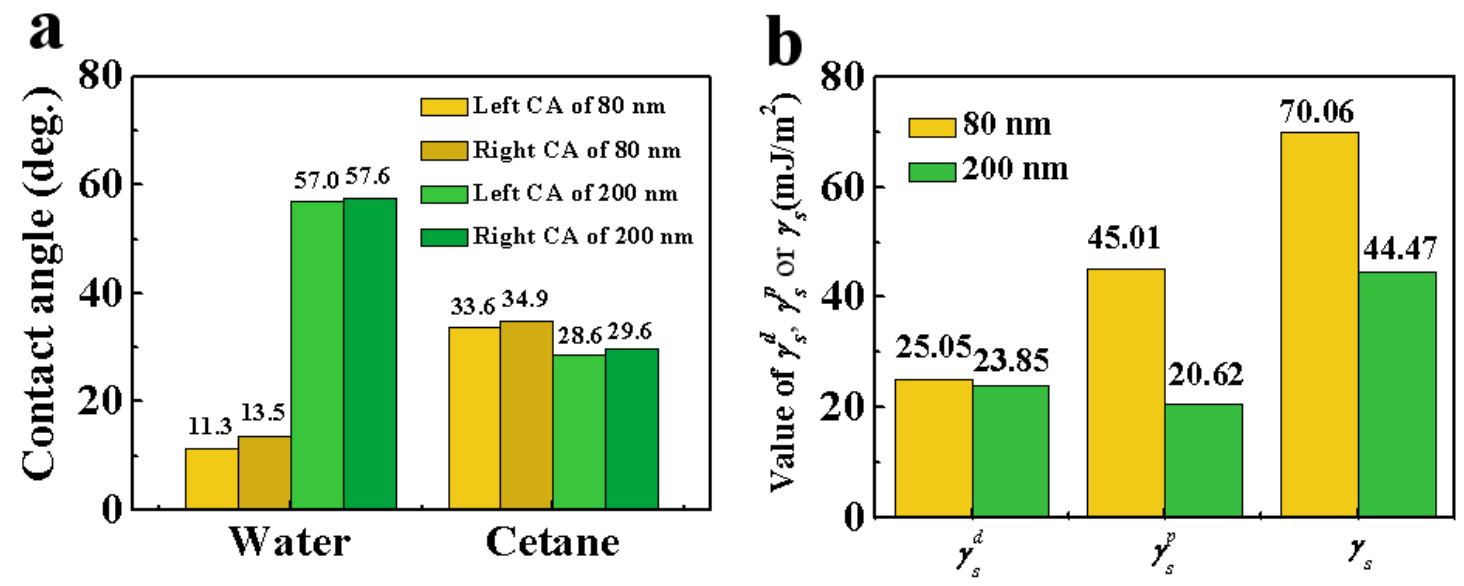

Fig. 6 (a) comparison of contact angle between the $\mathrm{BaTiO}_{3}$ powders and (b) $\gamma_{s}^{d}, \gamma_{s}^{d}, \gamma_{s}^{p}$ and $\gamma_{s}$ of the $\mathrm{BaTiO}_{3}$ powders.

\subsection{The apparent activation energy}

By studying the surface free energy of $\mathrm{BaTiO}_{3}$ powders, it can be found that the 
$G$ is relatively low, indicating that sintering cannot proceed spontaneously. It needs to be triggered at a certain sintering temperature before sintering can proceed. The sintering temperature is usually determined by the apparent activation energy of the system, so low-temperature sintering can be illustrated by calculating the apparent activation energy. Determining the sintering mechanism is the prerequisite for calculating the apparent activation energy [37]. Generally, the ceramic sintering mechanisms are divided into solid phase sintering and liquid phase sintering. Since the binary particle size self-assembly system does not introduce a liquid phase sintering aid, it may be a solid phase sintering mechanism. To illustrate it, TEM was used to characterize the ceramics obtained at different dwelling times (Fig. 7). With the extension of the dwelling times, the $\mathrm{BaTiO}_{3}$ particles evolve from quasi-spherical into polyhedral grains with obvious grain boundaries gradually. Simultaneously, the pores gradually decreased until disappeared, indicating that the ceramic densification is enhanced. In addition, the proportion of small size grains gradually decreases, and the proportion of large size grains increases, eventually forming uniform size grains. The results show that the $80 \mathrm{~nm} \mathrm{BaTiO}_{3}$ powders promote the mass transfer process, then trigger the external growth of the $200 \mathrm{~nm} \mathrm{BaTiO}_{3}$ powders, leading to reduce the number of pores and complete the densification. During the whole sintering process, only solid phase powder participated, and no liquid phase was found in TEM characterization. Therefore, it is a typical solid phase sintering, which conforms to the evaporation-condensation mass transfer mechanism. This mass transfer mechanism means that the binary system $\mathrm{BaTiO}_{3}$ powders have different vapor pressures due to 
the different radii of curvature of the surface and neck, which makes the gas phase with a mass transfer trend. Because the small size powders are interstitial in the gap formed by the large size powders, there is a positive radius of curvature on the surface of the large one, and there is a negative radius of curvature (sintering neck) at the junction of the large and small powders. The substance can migrate and condense from the convex surface to the concave surface (sintering neck) by evaporation, so that the sintering neck is gradually filled $[20-22,36]$. Additionally, the size of small size grains are quite different from that of large ones, so that the size of large ones grows slowly, thereby balancing the contradiction between densification and grain growth.
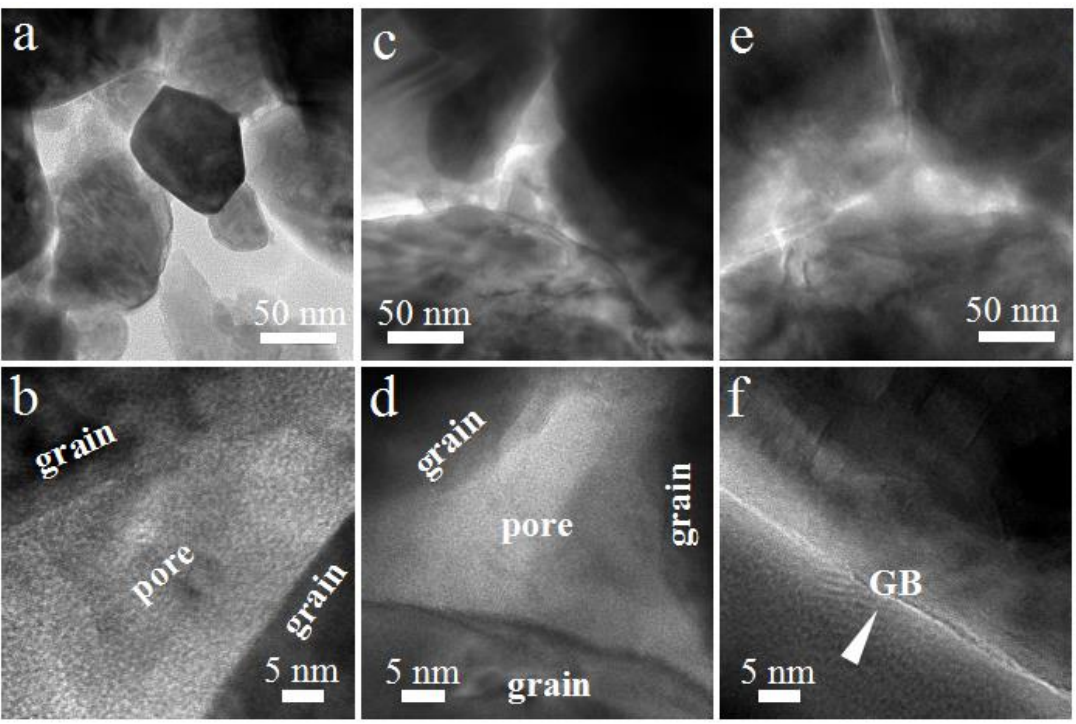

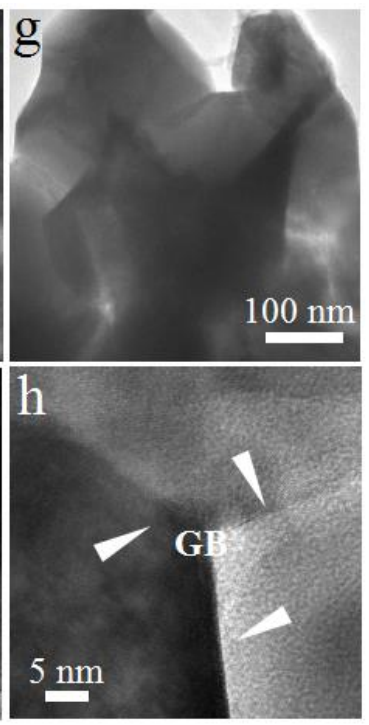

Fig. 7 TEM micrographs of the ceramics with the powders ratios of 1:1 sintered at $1000{ }^{\circ} \mathrm{C}$ for $2 \mathrm{~h}$ to $14 \mathrm{~h}:(\mathrm{a}, \mathrm{b}) 2 \mathrm{~h},(\mathrm{c}, \mathrm{d}) 6 \mathrm{~h},(\mathrm{e}, \mathrm{f}) 10 \mathrm{~h}$ and $(\mathrm{g}, \mathrm{h}) 14 \mathrm{~h}$.

The Arrhenius equation is used to calculate the apparent activation energy. For the process of solid phase sintering, the grain growth process follows the following relationship [38]: 


$$
G^{N}-G_{0}^{N}=t K_{0} e^{-\frac{Q}{R T}}
$$

Where $G$ is the average grain size of the ceramic, $G_{0}$ is the initial grain size, $N$ is the grain growth kinetic index, $t$ is the holding time, $K_{0}$ is the constant related to atom migration, and $Q$ is the apparent activation energy, $R$ represents Avogadro's constant, $T$ is the sintering temperature. When the sintering starts, the powders have not yet become grains. It can be considered that $G_{0}=0$, substituting it into the equation (6), the following equation can be obtained [38]:

$$
n \log G=\left(\log K_{0}-0.434 \frac{Q}{R T}\right)+\log t
$$

Equation (7) shows that under isothermal conditions, the grain size has a linear relationship with the dwelling time. Substituting the values of grain size into equation (7), $n=3$ can be obtained. Therefore, equation (7) can be rewritten as:

$$
\log \left(\frac{G^{3}}{t}\right)=\log K_{0}-\frac{0.434 Q}{R}\left(\frac{1}{T}\right)
$$

Then substituting the values of grain size into equation (8), the value $(360 \mathrm{~kJ} / \mathrm{mol})$ of $Q$ can be calculated by linear fitting (Fig. 8). Hotta Y [36] reported that using $150 \mathrm{~nm}$ $\mathrm{BaTiO}_{3}$ powders for traditional sintering, the $Q$ value of the system is $840 \mathrm{~kJ} / \mathrm{mol}$. It is more than twice that of the binary particle size self-assembly way. Even if the size of $\mathrm{BaTiO}_{3}$ powders is refined to $140 \mathrm{~nm}$ by ball milling, the $Q$ value calculated by the traditional sintering method is $420 \mathrm{~kJ} / \mathrm{mol}$, which is $80 \mathrm{~kJ} / \mathrm{mol}$ higher than that of the binary particle size self-assembly way. Thus, the fine-grained ceramics with high relative density can be obtained at a lower sintering temperature due to the low apparent activation energy. 


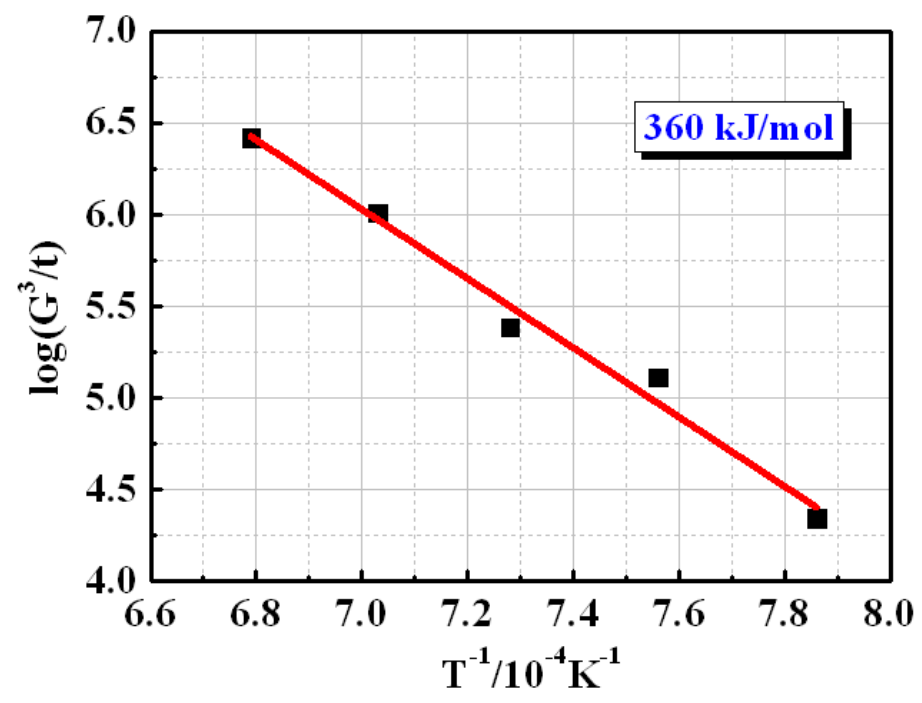

Fig. 8 Arrhenius equation linear fitting diagram.

Fig. 9 is a comparison diagram of the synthetic routes of $\mathrm{BaTiO}_{3}$ ceramics by traditional sintering method and binary particle size self-assembly sintering method. Only using pure $200 \mathrm{~nm} \mathrm{BaTiO}_{3}$ powders for sintering through the traditional sintering method, it is difficult to obtain dense ceramics at $1000{ }^{\circ} \mathrm{C}$ due to insufficient sintering force and high apparent activation energy. The binary particle size self-assembly sintering method uses $80 \mathrm{~nm} \mathrm{BaTiO}$ powders to improve the sintering force and reduce the apparent activation energy, which can balance the contradiction between densification and grain growth. So, fine-grained $\mathrm{BaTiO}_{3}$ ceramics with relative high relative density can be prepared under low sintering temperature. 


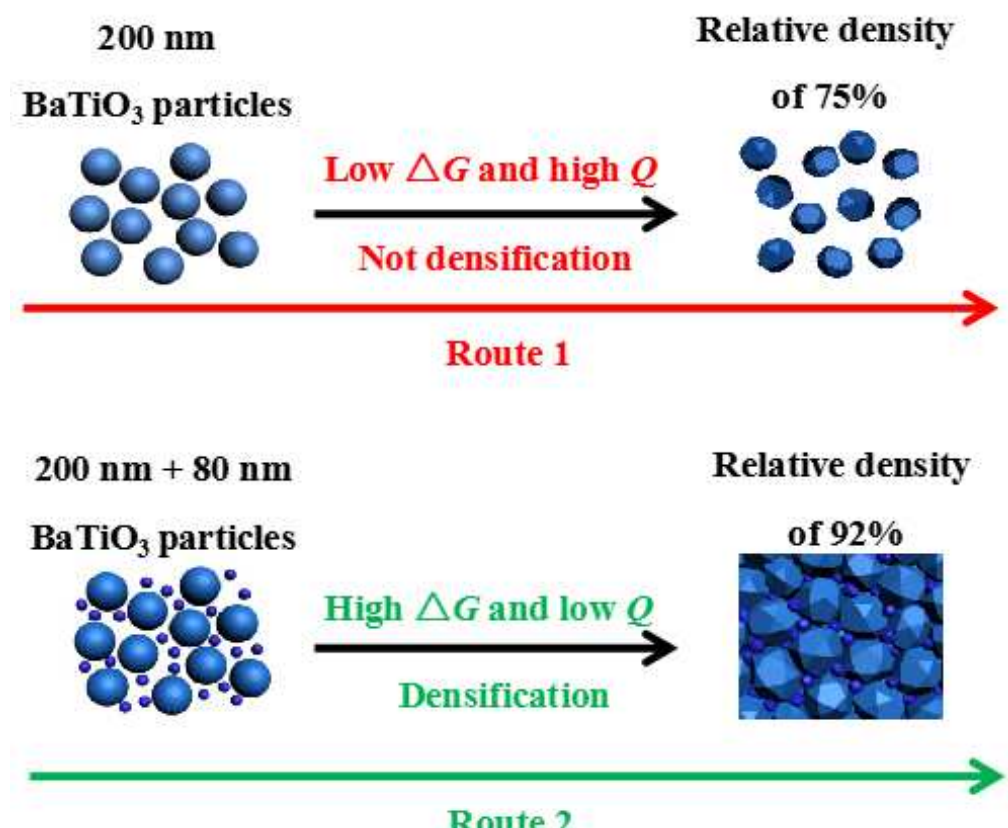

Fig. 9 Schematic diagram of the comparison of the two routes.

\section{Conclusion}

In this work, we take the $200 \mathrm{~nm}$ and $80 \mathrm{~nm} \mathrm{BaTiO}_{3}$ powders as the research model for combination and co-sintering. When the powder ratio is $1: 1$, the fine-grained ceramics $(252 \mathrm{~nm})$ with high relative density $(92 \%)$ can be obtained. The TEM characterization confirmed that the synthesis process satisfies the solid-phase sintering mechanism. The contact angle method is applied to determine that the surface energy of the binary particle size system is $127.56 \mathrm{~J} / \mathrm{mol}$, which can play a role in grain boundary diffusion without causing grain boundary migration. The intermediate surface energy is an important reason for balancing the densification and grain growth. The value of the apparent activation energy $(Q)$ with $360 \mathrm{~kJ} / \mathrm{mol}$ at $1000{ }^{\circ} \mathrm{C}$ can be calculated by the Arrhenius equation. The relative low $Q$ is the reason why the ceramics can be sintered at a relative low temperature $\left(1000{ }^{\circ} \mathrm{C}\right)$.

\section{Conflicts of interest}


There are no conflicts of interest to declare.

\section{Acknowledgments}

This work was supported by the National Natural Science Foundation of China (Grant No.21071115), the Shaanxi Natural Science Foundation (Grant No.2020JZ-44), and the Key Science and Technology Innovation Team of Shaanxi Province (Grant No.2019TD-007).

\section{References}

[1] J. L. Li, F. Li, Z. Xu, S. J. Zhang, Multilayer lead-free ceramic capacitors with ultrahigh energy density and effciency. Adv. Mater. 30(32), 1802155.1-1802155.7 (2018).

[2] X. H. Hao, A review on the dielectric materials for high energy-storage application. J. Adv. Die. 3(1): 1330001-1330014 (2013).

[3] M. X. Zhou, R. H. Liang, Z. Y. Zhou, X. L. Dong, Novel BaTiO3-based lead-free ceramic capacitors featuring high energy storage density, high power density, and excellent stability. J. Mater. Chem. C 6(31): 8528-8537 (2018).

[4] G. Wang, J. L. Li, X. Zhang, Z. M. Fan, F. Yang, A. Feteira, D. Zhou, D. C. Sinclair, T. Ma, X. L. Tan, D. W. Wang, I. M. Reaney, Ultrahigh energy storage density lead-free multilayers by controlled electrical homogeneity. Energ. Environ. Sci. 12(2): 582-588 (2019).

[5] Y. H. Huang, Y. J. Wu, B. Liu, T. N. Yang, J. J. Wang, J. Li, L. Q. Chen, X. M. Chen, From core-shell $\mathrm{Ba} 0.4 \mathrm{Sr}_{0.6} \mathrm{TiO}_{3} @ \mathrm{SiO}_{2}$ particles to dense ceramics with 
high energy storage performance by spark plasma sintering. J. Mater. Chem. A 6(10): 4477-4484 (2018).

[6] C. J. Xiao, Z. H. Chi, S. M. Feng, F. Y. Li, L. C. Chen, C. Q. Jin, X. H. Wang, L. T. Li, R. Z. Chen, Ferroelectricity of $30 \mathrm{~nm} \mathrm{BaTiO}_{3}$ ceramics prepared by high pressure sintering. J. Electroceram. 21(1-4): 39-42 (2008).

[7] N. E. Horr, Z. Valdez-Nava, C. Tenailleau, S. Guillemet-Fritscha, Microstructure of $\mathrm{Ba}_{1-x} \mathrm{La}_{x} \mathrm{TiO}_{3-\delta}$ ceramics sintered by spark plasma sintering. J. Eur. Ceram. Soc. 31(6): 1087-1096 (2011).

[8] H. Guo, J. Guo, A. Baker, C. A. Randall, Hydrothermal-assisted cold sintering process: a new guidance for low-temperature ceramic sintering. ACS Appl. Mater. Inter. 8(32): 20909-20915 (2016).

[9] N. J. Lóh, L. Simão, C. A. Faller, A. D. NoniJr, O. R. K. Montedo, A review of two-step sintering for ceramics. Ceram. Int. 42(11): 12556-12572 (2016).

[10] N. Yu, Y. Hidehiro, U. Akinori, T. Tokunaga, K. Sasaki, T. Yamamoto, Electric-current-controlled synthesis of $\mathrm{BaTiO}_{3}$. J. Am. Ceram. Soc. 100(9): 3843-3850 (2017).

[11] T. K. Hyun, H. H. Young, Sintering of nanocrystalline $\mathrm{BaTiO}_{3}$. Ceram. Int. 30(7): 1719-1723 (2004).

[12] M. Legallais, S. Fourcade, U. C. Chung, D. Michau, M. Maglione, F. Mauvy, C. Elissalde, Fast re-oxidation kinetics and conduction pathway in spark plasma sintered ferroelectric ceramics. J. Eur. Ceram. Soc. 38(2): 543-550 (2018).

[13] M. Q. Xie, Y. X. Che, K. Liu, L. X. Jiang, L. M. Xue, Caking-inspired cold 
sintering of plastic supramolecular films as multifunctional platforms. Adv. Funct. Mater. 28(36): 1803370.1-1803370.8 (2018).

[14] J. Guo, H. Z. Guo, A. L. Baker, M. T. Lanagan, E. R. Kupp, G. L. Messing, C. A. Randall, Cold sintering: a paradigm shift for processing and integration of ceramics. Angew. Chem. Int. Edit. 128(38): 11629-11633 (2016).

[15] H. Guo, A. Baker, J. Guo, M. T. Lanagan, E. R. Kupp, G. L. Messing, C. A. Randall, Cold sintering process: a novel technique for low-temperature ceramic processing of ferroelectrics. J. Am. Ceram. Soc. 99(11): 3489-3507 (2016).

[16] Y. Huan, X. H. Wang, J. Fang, L. T. Li, Grain size effects on piezoelectric properties and domain structure of $\mathrm{BaTiO}_{3}$ ceramics prepared by two step sintering. J. Am. Ceram. Soc. 96(11): 3369-3371 (2013).

[17] Y. Huan, X. H. Wang, J. Fang, L. T. Li, Grain size effect on piezoelectric and ferroelectric properties of $\mathrm{BaTiO}_{3}$ ceramics. J. Eur. Ceram. Soc. 34(5): $1445-1448(2014)$

[18] D. Tingaud, P. Jenei, A. Krawczynska, F. Mompiou, J. Gubicza, G. Dirras, Investigation of deformation micro-mechanisms in nickel consolidated from a bimodal powder by spark plasma sintering. Mater. Charact. 99: 118-127 (2015).

[19] Y. C. Shan, Z. H. Zhang, X. N. Sun, J. J. Xu, Q. H. Qin, J. T. Li, Fast densification mechanism of bimodal powder during pressureless sintering of transparent AlON ceramics. J. Eur. Ceram. Soc. 36(3): 671-678 (2016).

[20] Y. Hirata, H. Fujita, T. Shimonosono, Compressive mechanical properties of partially sintered porous alumina of bimodal particle size system. Ceram. Int. 
43(2): 1895-1903 (2017).

[21] J. W. Oh, Y. J. Seong, D. S. Shin, S. J. Park, Investigation and two-stage modeling of sintering behavior of nano/micro-bimodal powders. Powder Technol. 352(15):42-52 (2019).

[22] H. Y. Xu, J. Zou, W. M. Wang, H. Wang, W. Ji, Z. Y. Fu, Densification mechanism and microstructure characteristics of nano- and micro- crystalline alumina by high-pressure and low temperature sintering. J. Eur. Ceram. Soc. 41(1): 635-645 (2021).

[23] X. Y. Zhai, Y. J. Chen, Y. Q. Ma, S. C. Sun, J. X. Liu, A new strategy of binary-size particles model for fabricating fine grain, high density and low resistivity ITO target. Ceram. Int. 46(9): 13660-13668 (2020).

[24] Q. Jin, B. Cui, X. T. Zhang, J. Wang, A binary particle self-assembly sintering method to realize controllable synthesis of fine-grained barium titanate ceramics. J. Electron. Mater. 2021, 50(1):325-335.

[25] Y. Yang, L. Gao, G. P. Lopez, B. B. Yellen, Tunable assembly of colloidal crystal alloys using magnetic nanoparticle fluids. Acs Nano 7(3): 2705-2716 (2013).

[26] A. A. Shah, M. Ganesan, J. Jocz, M. J. Solomon, Direct current electric field assembly of colloidal crystals displaying reversible structural color. Acs Nano, 8(8): 8095-8103 (2014).

[27] H. Cong, B. Yu, J. Tang, Z. J. Li, X. S. Liu, Current status and future developments in preparation and application of colloidal crystals. Chem. Soc. 
Rev. 42(19): 7774-7800 (2013).

[28] H. P. Ding, Z. K. Zhao, J. S. Jin, L. Deng, P. Gong, X. Y. Wang, Densification mechanism of Zr-based bulk metallic glass prepared by two-step spark plasma sintering. J. Alloy. Compd. 850: 156724-156736 (2021).

[29] A. Ndayishimiye, M. Y. Sengul, S. H. Bang, K. Tsuji, K. Takashima, T. H. Beauvoir, D. Denux, J. M. Thibaud, A. C. T. Duin, C. Elissalde, G. Goglio, C. A. Randall, Comparing hydrothermal sintering and cold sintering process: Mechanisms, microstructure, kinetics and chemistry. J. Eur. Ceram. Soc. 40(4): 1312-1324 (2020).

[30] J. M. Liu, H. Rongxia, R. B. Zhang, G. H. Liu, X. L. Wang, Z. D. Jia, L. M. Wang, Mechanism of flash sintering with high electric field: In the view of electric discharge and breakdown. Scripta Mater. 187: 93-96 (2020).

[31] M. Haug, F. Bouvill, C. Ruiz-Agudo, J. Avaro, D. Gebauer, A. R. Studart, Cold densification and sintering of nanovaterite by pressing with water. J. Eur. Ceram. Soc. 40(3): 893-900 (2020).

[32] H. Guo, A. Baker, J. Guo, C. A. Randall, Cold sintering process: a novel technique for low-temperature ceramic processing of ferroelectrics. J. Am. Ceram. Soc. 99(11): 3489-3507 (2016).

[33] A. Kozbia, Z. T. Li, C. Conaway, R. McGinley, S. Dhingra, V. Vahdat, F. Zhou, B. D’Urso, H. T. Liu, L. Li, Study on the surface energy of graphene by contact angle measurements. Langmuir 30(28): 8598-8606 (2014).

[34] S. Moradi, P. Englezos, S. G. Hatzikiriakos, Contact angle hysteresis of 
non-flattenedtop micro/nanostructures. Langmuir 30(11): 3274-3284 (2014).

[35] X. Y. Kang, R. Floyd, S. Lowum, M. Cabral, E. Dickey, J. P. Maria, Mechanism studies of hydrothermal cold sintering of zinc oxide at near room temperature. J. Am. Ceram. Soc. 102(8): 4459-4469 (2019).

[36] Y. Hotta, C. Duran, K. Sato, T. Nagaoka, K. Watari, Densification and grain growth in $\mathrm{BaTiO}_{3}$ ceramics fabricated from nanoparticles synthesized by ball-milling assisted hydrothermal reaction. J. Eur. Ceram. Soc. 28(3): 599-604 (2008).

[37] L. Balice, M. Cologna, F. Audubert, J. L. Hazemann, Densification mechanisms of $\mathrm{UO}_{2}$ consolidated by spark plasma sintering. J. Eur. Ceram. Soc. 41(1): 719-728 (2021)

[38] J. P. Maria, X. Y. Kang, R. D. Floyd, E. C. Dickey, Cold sintering: current status and prospects. J. Materi. Res. 32(17): 1-4 (2017). 
Figures

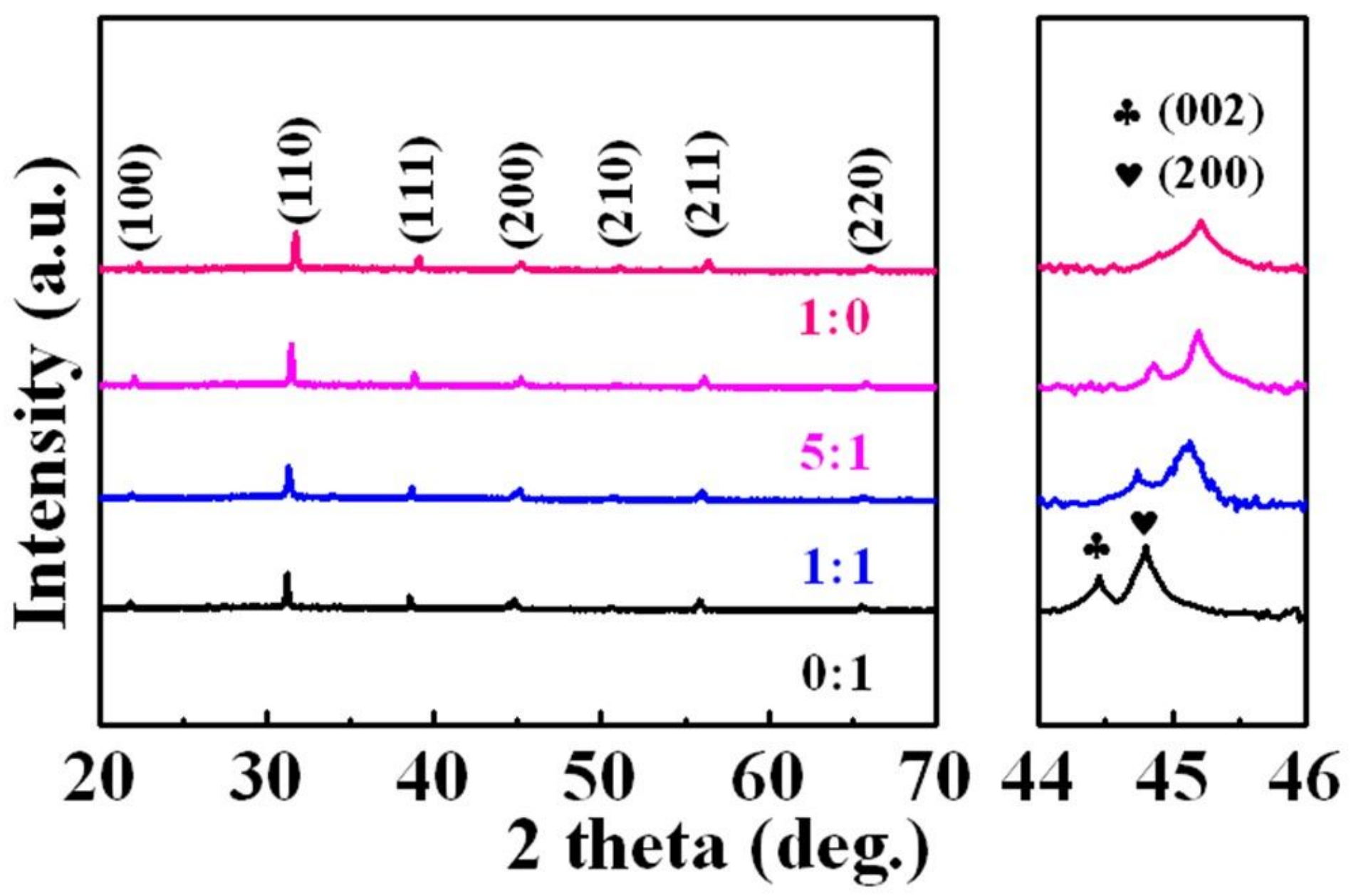

Figure 1

XRD patterns of the BaTiO3 ceramics obtained by different ratios of the BaTiO3 powders. The ratio of 0:1 represents the ratio of $200 \mathrm{~nm}$ powders to $80 \mathrm{~nm}$ powders. Other ratios have the same meanings.
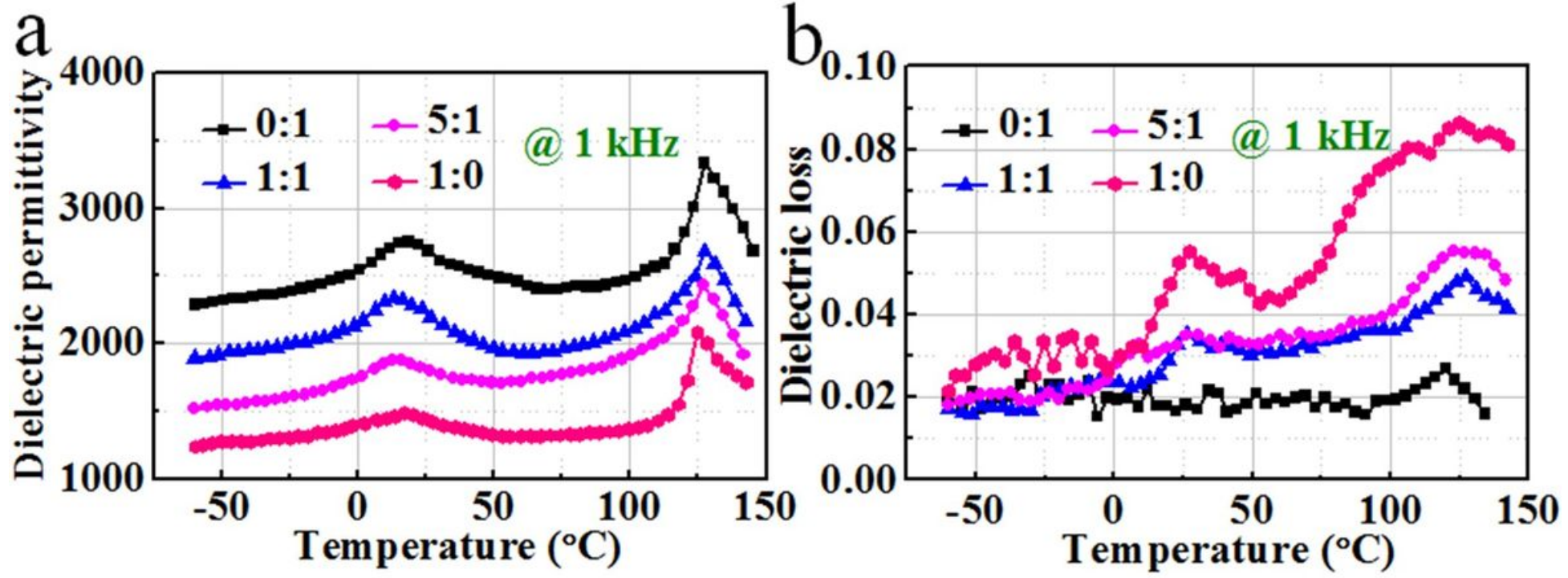
Figure 2

(a) The dielectric permittivity and (b) the dielectric loss of the samples obtained by different ratios of the BaTiO3 powders.
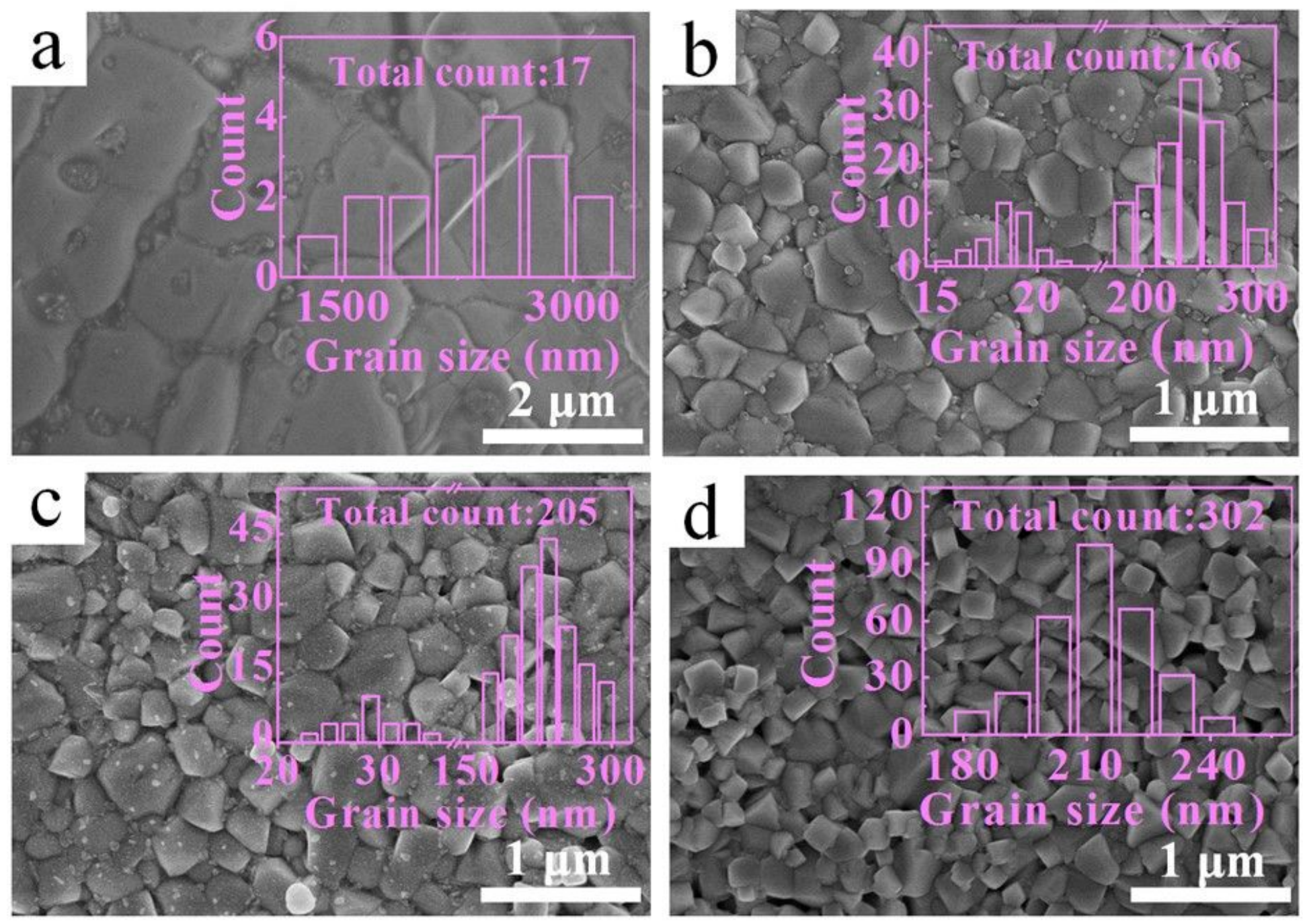

Figure 3

SEM micrographs of the BaTiO3 ceramics obtained by different ratios of the BaTiO3 powders: (a) 0:1, (b) $1: 1$, (c) $5: 1$ and (e) 1:0. 

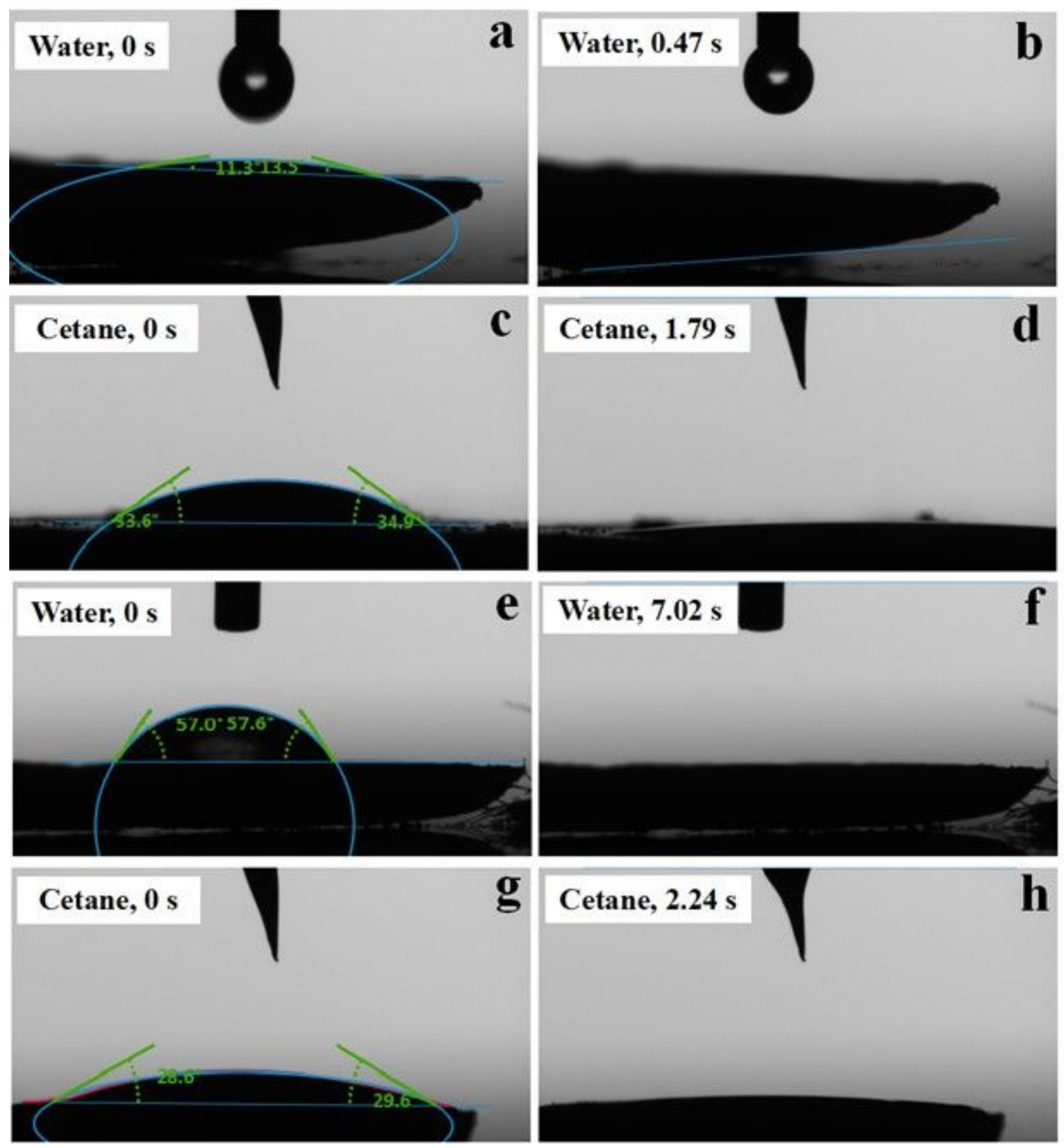

Figure 4

CA images of the $80 \mathrm{~nm}$ BaTiO3 powders: (a) start (water), (b) end (water), (c) start (hexadecane) and (d) end (hexadecane), CA images of the $200 \mathrm{~nm}$ BaTiO3 powders: (e) start (water), (f) end (water), (g) start (hexadecane) and ( $h$ ) end (hexadecane). 


\section{Vapor \\ $\gamma_{l v}$}

\section{Liquid}

$\gamma_{s l} \theta$

\section{Solid}

Figure 5

Schematic diagram of the contact angle.
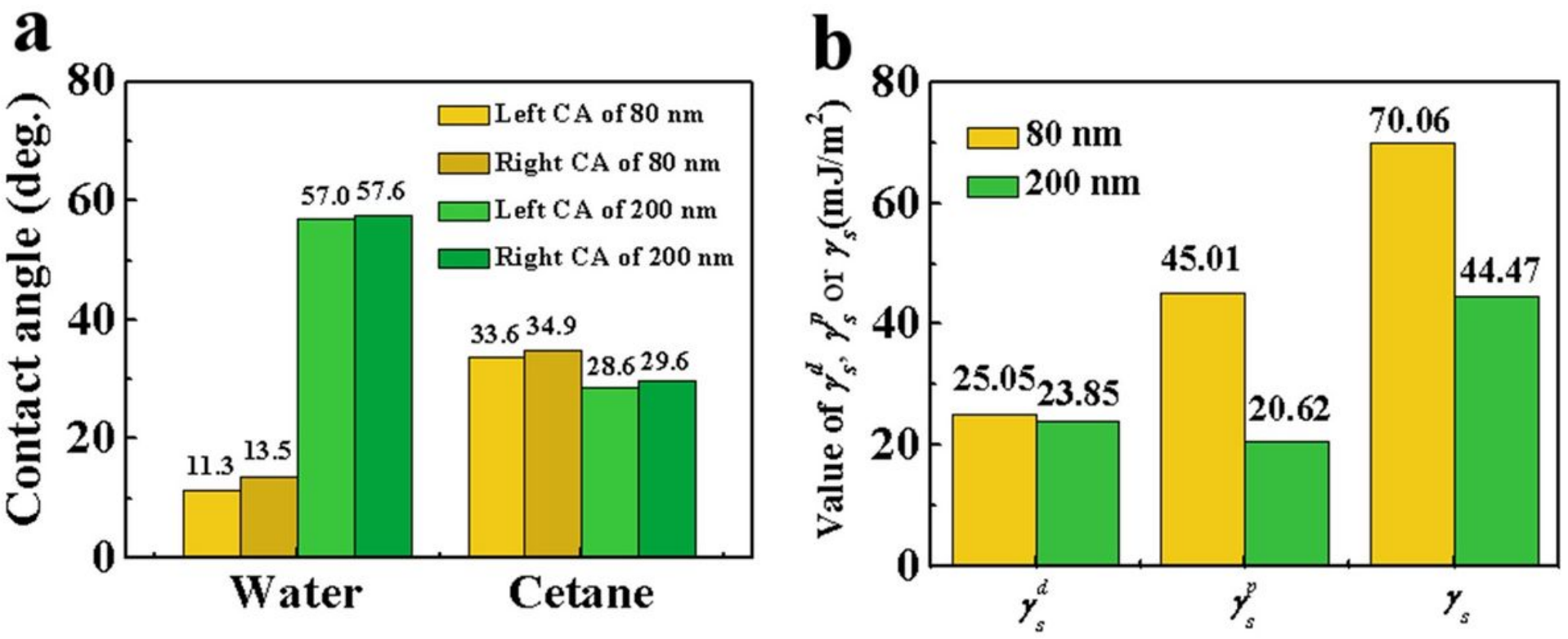

Figure 6

Please see the Manuscript Doc file for the complete figure caption. 

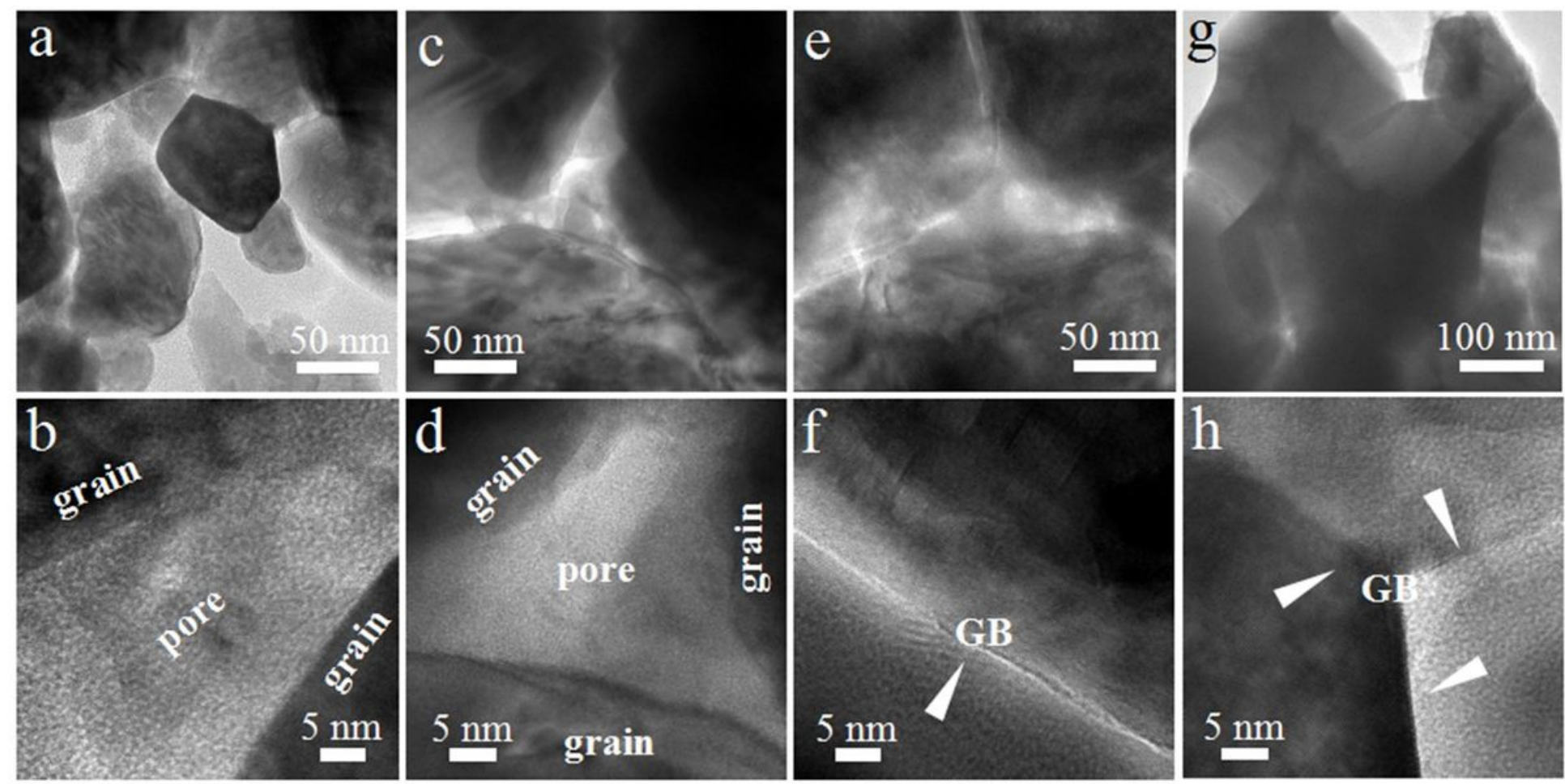

Figure 7

TEM micrographs of the ceramics with the powders ratios of $1: 1$ sintered at $1000^{\circ} \mathrm{C}$ for $2 \mathrm{~h}$ to $14 \mathrm{~h}:(\mathrm{a}, \mathrm{b})$ $2 \mathrm{~h},(\mathrm{c}, \mathrm{d}) 6 \mathrm{~h},(\mathrm{e}, \mathrm{f}) 10 \mathrm{~h}$ and $(\mathrm{g}, \mathrm{h}) 14 \mathrm{~h}$. 


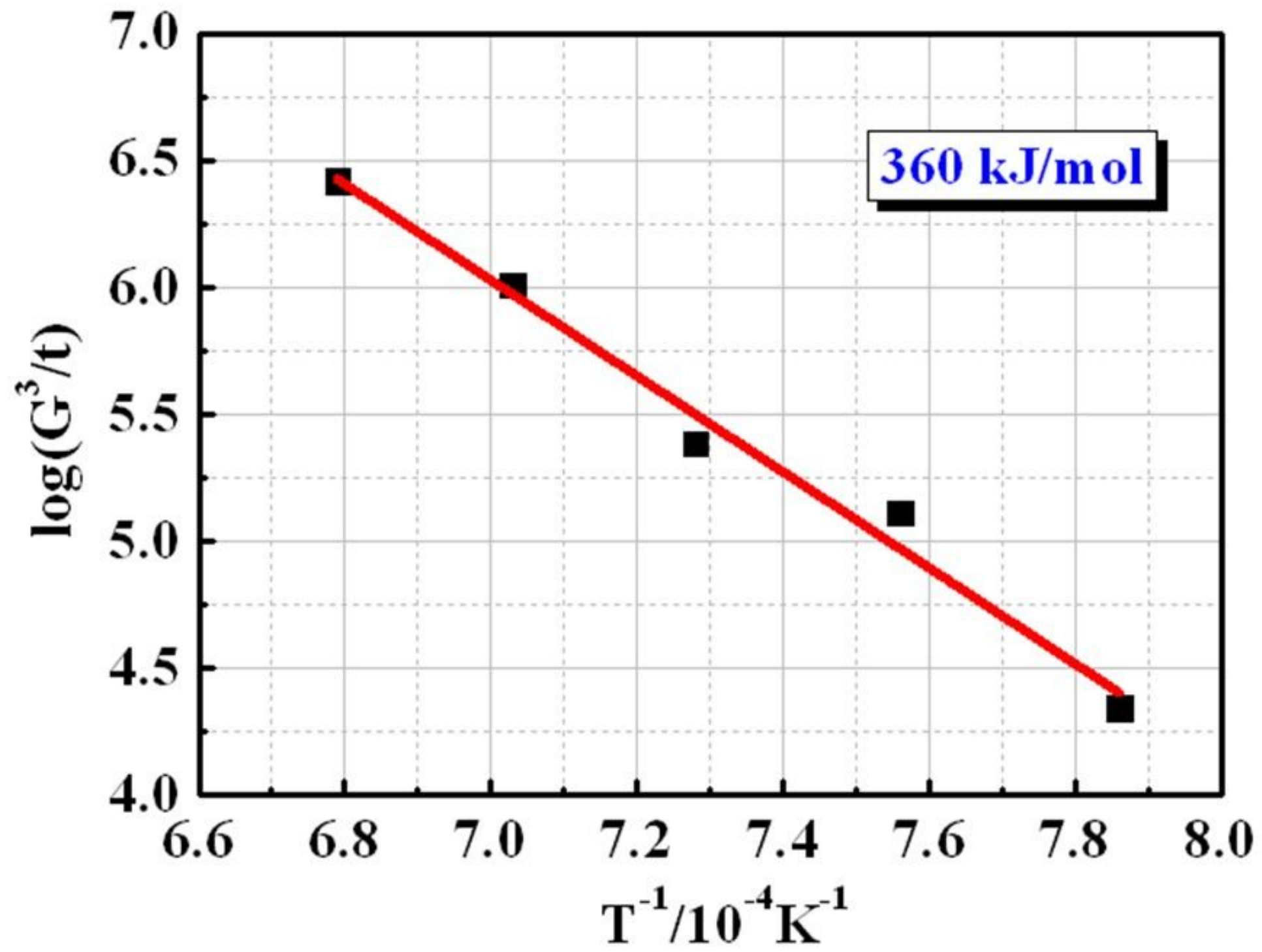

Figure 8

Arrhenius equation linear fitting diagram. 
$200 \mathrm{~nm}$

$\mathrm{BaTiO}_{3}$ particles

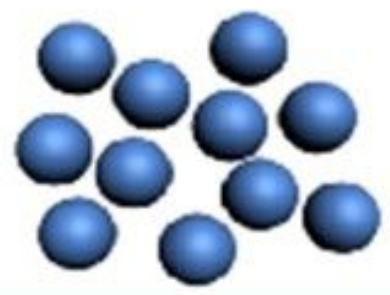

Low $\triangle G$ and high $Q$

Not densification
Relative density

of $75 \%$

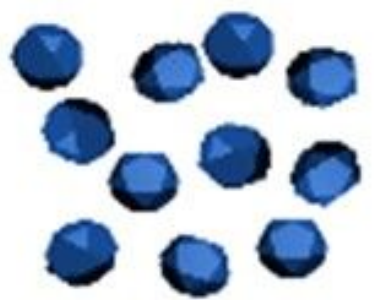

\section{Route 1}

$200 \mathrm{~nm}+80 \mathrm{~nm}$

\section{$\mathrm{BaTiO}_{3}$ particles}

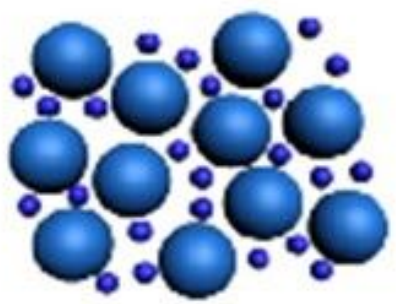

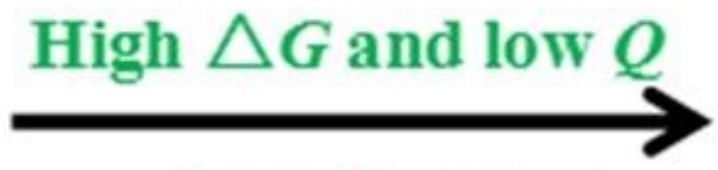

Densification
Relative density

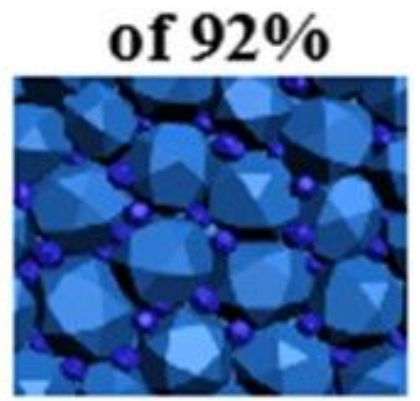

\section{Route 2}

Figure 9

Schematic diagram of the comparison of the two routes.

\section{Supplementary Files}

This is a list of supplementary files associated with this preprint. Click to download.

- Supplementarylnformation.doc 